\title{
Diel metabolomics analysis of a hot spring chlorophototrophic microbial mat leads to new hypotheses of community member metabolisms
}

\section{OPEN ACCESS}

Edited by:

William P. Inskeep,

Montana State University, USA

Reviewed by:

Jason Warren Cooley,

University of Missouri, USA

Hua Xiang,

Chinese Academy of Sciences, China

${ }^{*}$ Correspondence:

Thomas O. Metz,

Pacific Northwest National Laboratory,

902 Battelle Blvd, PO Box 999,

MSIN K8-98, Richland, WA 99352,

USA

thomas.metz@pnnl.gov

${ }^{\dagger}$ Present Address:

Eric D. Becraft,

Department of Biological Sciences,

Northern Illinois University,

DeKalb, USA

Specialty section:

This article was submitted to

Microbial Physiology and Metabolism,

a section of the journal

Frontiers in Microbiology

Received: 23 December 2014 Accepted: 02 March 2015

Published: 17 April 2015

Citation:

Kim Y-M, Nowack S, Olsen MT,

Becraft ED, Wood JM, Thiel V,

Klapper I, Kühl M, Fredrickson JK,

Bryant DA, Ward DM and Metz TO (2015) Diel metabolomics analysis of a

hot spring chlorophototrophic

microbial mat leads to new

hypotheses of community member metabolisms. Front. Microbiol. 6:209.

doi: 10.3389/fmicb.2015.00209
Young-Mo Kim ${ }^{1}$, Shane Nowack ${ }^{2,3}$, Millie T. Olsen ${ }^{2}$, Eric D. Becraft ${ }^{2 \dagger}$, Jason M. Wood ${ }^{2}$, Vera Thiel ${ }^{4}$, Isaac Klapper ${ }^{3,5}$, Michael Küh/6,7, James K. Fredrickson ${ }^{1}$, Donald A. Bryant ${ }^{4,8}$, David M. Ward ${ }^{2}$ and Thomas O. Metz ${ }^{1 *}$

'Biological Sciences Division, Pacific Northwest National Laboratory, Richland, WA, USA, ${ }^{2}$ Department of Land Resources and Environmental Sciences, Montana State University, Bozeman, MT, USA, ${ }^{3}$ Department of Mathematical Sciences, Montana State University, Bozeman, MT, USA, ${ }^{4}$ Department of Biochemistry and Molecular Biology, The Pennsylvania State University, University Park, PA, USA, ${ }^{5}$ Department of Mathematics, Temple University, Philadelphia, PA, USA, ${ }^{6}$ Marine Biological Section, Department of Biology, University of Copenhagen, Helsingør, Denmark, ${ }^{7}$ Plant Functional Biology and Climate Change Cluster, University of Technology Sydney, Ultimo, NSW, Australia, ${ }^{8}$ Department of Chemistry and Biochemistry, Montana State University, Bozeman, MT, USA

Dynamic environmental factors such as light, nutrients, salt, and temperature continuously affect chlorophototrophic microbial mats, requiring adaptive and acclimative responses to stabilize composition and function. Quantitative metabolomics analysis can provide insights into metabolite dynamics for understanding community response to such changing environmental conditions. In this study, we quantified volatile organic acids, polar metabolites (amino acids, glycolytic and citric acid cycle intermediates, nucleobases, nucleosides, and sugars), wax esters, and polyhydroxyalkanoates, resulting in the identification of 104 metabolites and related molecules in thermal chlorophototrophic microbial mat cores collected over a diel cycle in Mushroom Spring, Yellowstone National Park. A limited number of predominant taxa inhabit this community and their functional potentials have been previously identified through metagenomic and metatranscriptomic analyses and in situ metabolisms, and metabolic interactions among these taxa have been hypothesized. Our metabolomics results confirmed the diel cycling of photorespiration (e.g., glycolate) and fermentation (e.g., acetate, propionate, and lactate) products, the carbon storage polymers polyhydroxyalkanoates, and dissolved gasses (e.g., $\mathrm{H}_{2}$ and $\mathrm{CO}_{2}$ ) in the waters overlying the mat, which were hypothesized to occur in major mat chlorophototrophic community members. In addition, we have formulated the following new hypotheses: (1) the morning hours are a time of biosynthesis of amino acids, DNA, and RNA; (2) photo-inhibited cells may also produce lactate via fermentation as an alternate metabolism; (3) glycolate and lactate are exchanged among Synechococcus and Roseiflexus spp.; and (4) fluctuations in many metabolite pools (e.g., wax esters) at different times of day result from species found at different depths within the mat responding to temporal differences in their niches.

Keywords: gas chromatography-mass spectrometry, metabolomics, microbial mats, polyhydroxyalkanoates, Roseiflexus, Synechococcus, wax esters 


\section{Introduction}

Microbial communities inhabiting extreme environments in Yellowstone National Park (YNP) have been investigated for more than half a century (Brock, 1972, 1998). In particular, chlorophototrophic (i.e., chlorophyll-based phototrophs) microbial mat communities present in the effluent channels of Octopus Spring and Mushroom Spring within the Lower Geyser Basin have been intensively studied (Brock, 1978; Ward et al., 2012). As a result of metagenomic (Klatt et al., 2011) and metatranscriptomic (Liu et al., 2011, 2012; Klatt et al., 2013) analyses, an objective and more complete understanding of the major taxa inhabiting the upper $2 \mathrm{~mm}$ of the $60-65^{\circ} \mathrm{C}$ regions of the Mushroom Spring mat, in terms of their contribution to the gene pool and their functional potentials, has emerged (Table 1). Cyanobacteria from the genus Synechococcus are the predominant primary producers driving metabolism in these communities via oxygenic photosynthesis (Klatt et al., 2011; Liu et al., 2011). Synechococcus spp. fix $\mathrm{CO}_{2}$ and synthesize, and possibly excrete, metabolites that are then consumed by (photo)-heterotrophic members of the community, including several Chloroflexi, especially Roseiflexus spp. (Table 1), which were formerly thought to be exclusively photoheterotrophs. However, genomics, metagenomics, and metatranscriptomics analyses have revealed that Roseiflexus spp. also have the genetic potential to fix $\mathrm{CO}_{2}$ (Klatt et al., 2007; Van Der Meer et al., 2010). Collectively, cyanobacteria and Roseiflexus spp. account for the majority of the biomass of the upper $0-2 \mathrm{~mm}$ portion of the mat community (Table 1), and thus they should have the greatest influence on the metabolites in this portion of the mat. Two additional Chloroflexi, Chloroflexus spp. and a novel, apparently phototrophic, Anaerolineae-like taxon, and two aerobic/microaerophilic, anoxygenic photoheterotrophs, Chloracidobacterium thermophilum (Bryant et al., 2007; Garcia Costas et al., 2012) and "Candidatus Thermochlorobacter aerophilum" (Liu et al., 2012), also occur in the upper photic layer of the mat. Non-chlorophyllous, heterotrophic bacteria have been detected in the upper mat community, but they are much less abundant (Liu et al., 2011), and are unlikely to strongly influence mat metabolites. Heterotrophs, together with the photoheterotrophic and photomixotrophic community members, can be considered potential consumers of metabolites produced by cyanobacteria and possibly other mat inhabitants.

Studies performed by Konopka (1992) and Nold and Ward (1996) showed that $\mathrm{CO}_{2}$-fixing chlorophototrophic community members undergo diel metabolic switching. Recently, metatranscriptomics analyses have provided a comprehensive view of diel transcription patterns in predominant mat taxa (Liu et al., 2011, 2012; Klatt et al., 2013), and have led to new hypotheses about Synechococcus spp. and Roseiflexus spp. metabolisms. For instance, Synechococcus spp. express genes involved in photosynthesis diurnally and have the genetic potential to produce glycogen, which they accumulate during the day (Van Der Meer et al., 2007). Extremely high irradiance during the day leads to $\mathrm{O}_{2}$ supersaturation combined with $\mathrm{CO}_{2}$ depletion (as indicated by elevated $\mathrm{pH}$ ), causing production and possible accumulation of toxic levels of glycolate, a common product of photorespiration (Bateson and Ward, 1988). Synechococcus spp. also have the genetic potential to conduct fermentation with production of lactate, acetate, ethanol and formate (Bhaya et al., 2007). When photosynthesis declines in the evening, $\mathrm{O}_{2}$ uptake by aerobically respiring community members exceeds $\mathrm{O}_{2}$ production and the mat becomes anoxic, except within the upper $\sim 150 \mu \mathrm{m}$. Fermentation genes, as well as genes involved in $\mathrm{N}_{2}$ fixation, are expressed at this time, consistent with measured $\mathrm{N}_{2}$ fixation driven by fermentative metabolism at night and by light in the early morning (Steunou et al., 2006, 2008).

Diurnal transcription patterns of the genes involved in $\mathrm{CO}_{2}$ fixation suggested that Roseiflexus spp. can conduct photomixotrophic metabolism, in which they combine $\mathrm{CO}_{2}$ fixation with assimilation of low-molecular weight organic compounds, possibly produced by Synechococcus spp. (Klatt et al., 2013). Other transcription patterns suggested that Roseiflexus spp. construct and decompose intracellular polymers, including glycogen, polyhydroxyalkanoates (PHAs) and possibly wax esters (genomic and metagenomic analyses show that Synechococcus spp. lack the ability to synthesize PHAs (Bhaya et al., 2007; Klatt et al., 2011). Because external reductants such as $\mathrm{H}_{2}$ and $\mathrm{H}_{2} \mathrm{~S}$ are not present in the oxic mid-day photic layers of the mat, it was further hypothesized that utilization of these intracellular storage polymers may provide reductants and organic intermediates for photomixotrophic $\mathrm{CO}_{2}$ incorporation during the day. As suggested by Bauld and Brock (1973), organic compounds produced by $\mathrm{CO}_{2-}$ fixing community members might be cross-fed to (photo)heterotrophic or mixotrophic mat community members. Little is known about metabolite exchange in the mat, although it has been shown that acetate, butyrate, ethanol, glycolate, lactate, and propionate are photoassimilated into filamentous community members (Anderson et al., 1987; Bateson and Ward, 1988).

Metabolomics has been successfully applied to characterize the metabolic responses of diverse organisms, both qualitatively and quantitatively, under various growth conditions (Koek et al., 2011). These measurements are increasingly used to study microbial communities (Mosier et al., 2013; Xie et al., 2013). In the current study, a combination of untargeted and targeted metabolomics analyses was performed to quantify five groups of metabolites. Volatile organic acids, polar metabolites, wax esters, and PHAs were measured in the mat, while selected dissolved gasses and inorganic ions were quantified in the overflowing water. Measurements of acetate, propionate, and glycolate in the mat, as well as $\mathrm{H}_{2}, \mathrm{CO}_{2}$, and $\mathrm{CH}_{4}$ in the water, were performed to test hypotheses regarding the production of these products during different parts of the diel cycle. Similarly, targeted measurements of wax esters and PHAs were performed to characterize these molecules as intracellular carbon and energy storage polymers that should undergo diel cycling if photomixotrophy occurs as hypothesized in Roseiflexus spp. (Klatt et al., 2013). Finally, untargeted metabolomics measurements were performed to identify and quantify polar metabolites extracted from the mat samples (intracellular) and interstitial fluids (extracellular) to identify additional metabolites that are changing during the diel cycle and that may be available for possible metabolic exchange among mat community members, respectively. In addition to 


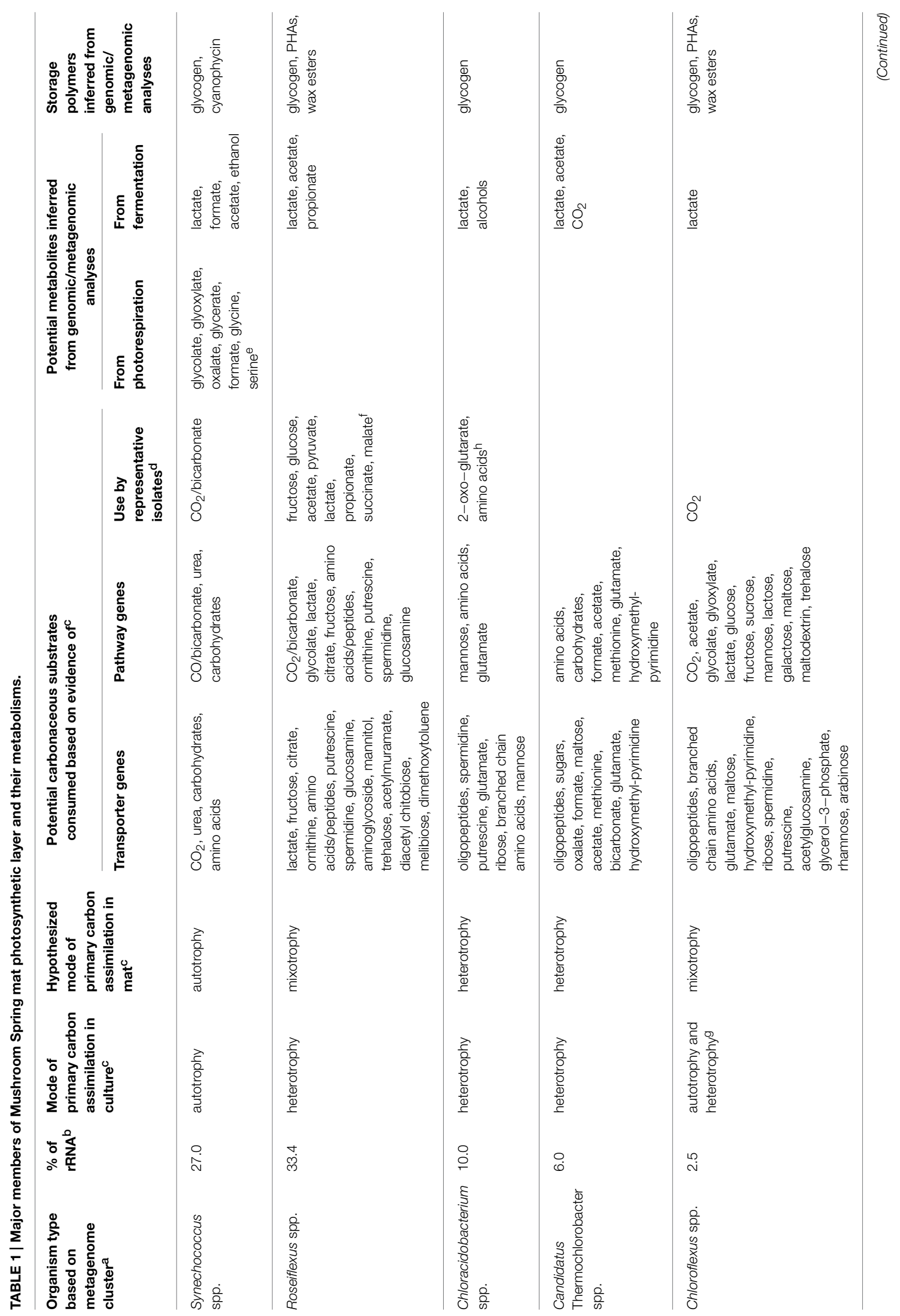




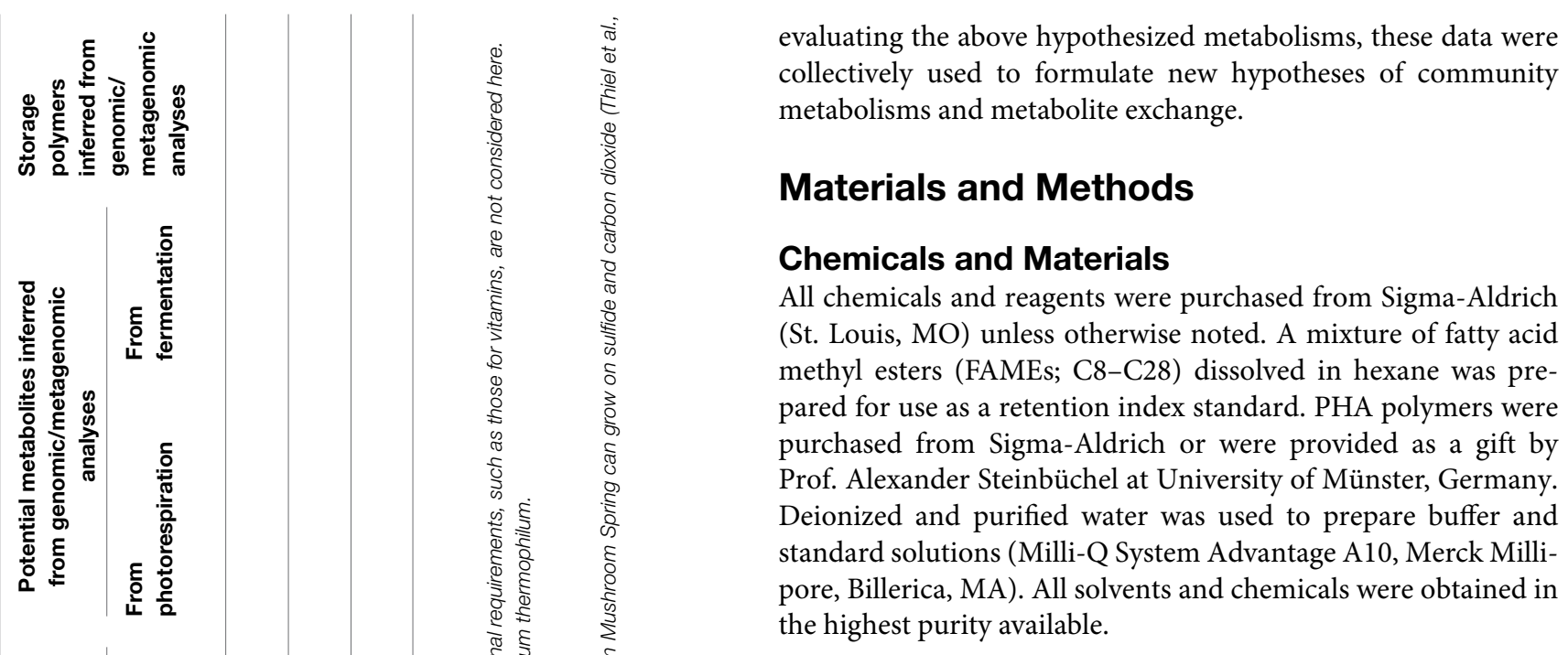

\section{Sample Collection Mat Samples}

For whole-mat (i.e., intracellular and extracellular metabolites combined) analyses of volatile organic acids, polar metabolites, wax esters, and PHAs, core samples were collected in from a microbial mat in the effluent channel of Mushroom Spring in the Lower Geyser Basin (YNP, WY) where the temperature of water in the sampling area varied from 58 to $62^{\circ} \mathrm{C}$ during the diel cycle. A cork-borer with a $8 \mathrm{~mm}$ inner diameter was used to collect the same volume of mat sample, and a razor blade was used to separate the top $5 \mathrm{~mm}$ of each mat core such that the analyses were focused on the top green phototrophic layer and the redorange undermat layers in the zone that contain most of the biological activity (Ward et al., 1987) (Figure 1). The samples were transferred to microcentrifuge tubes and immediately frozen in a Dewar containing liquid nitrogen. Mat samples were collected in triplicate at 14 time points between 13:30 h on September 21, 2012 and 11:00 h the following day.

For analyses of extracellular metabolites, mat core samples were collected at 03:00, 09:00, 13:00, and 19:00 h ( $n=6$, each) during the same diel cycle. Once collected, three core samples from each time point were immediately frozen as described above for use as unrinsed controls, while the remaining three samples were transferred to $15 \mathrm{~mL}$ Falcon tubes containing $1 \mathrm{~mL}$ of spring water that had been filtered through a $0.2-\mu \mathrm{m}$ filter. Since the $68^{\circ} \mathrm{C}$ source pool of Mushroom Spring is lined with mat, in order to avoid metabolites that might have diffused from the mat to overflowing water, we used water from the source pool $\left(92^{\circ} \mathrm{C}\right)$ of chemically similar Octopus Spring (Papke et al., 2003), which is well upstream of photosynthetic mats (maximum range of $72-74^{\circ} \mathrm{C}$ ). This water did not contain significant levels of any of the organic compounds detected in this study. The re-suspended mat cores were then quickly disrupted onsite by vigorous shaking, and the biomass and rinse water were then immediately separated using a centrifuge $(16,025 \times g$ for $5 \mathrm{~min})$. The supernatant was transferred to a clean microcentrifuge tube and the rinsed biomass and the rinse water samples were immediately frozen with liquid nitrogen. All samples were stored at $-80^{\circ} \mathrm{C}$ until further processing. This process did not 

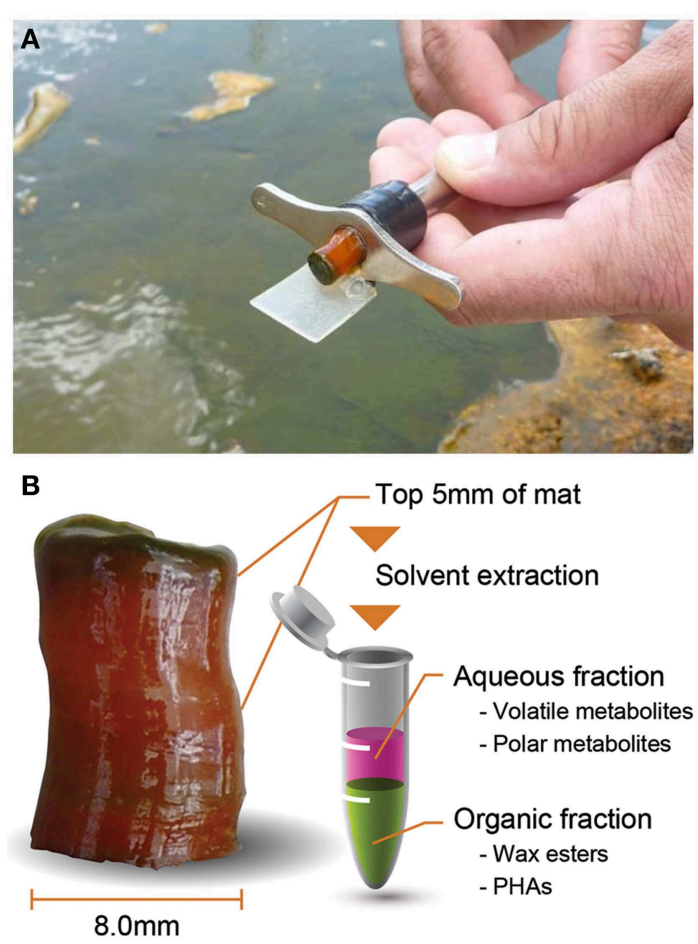

FIGURE 1 | Core sampling using a cork-borer in Mushroom Spring phototrophic mat (A) and longitudinal view of core sample and brief analytical scheme (B).

result in release of metabolites identified in analyses of biomass, suggesting that it did not cause leakage of constituents from intact cells.

\section{Water Samples}

Duplicate water samples were collected at 03:00, 07:00, 09:00, 11:00, 13:00, 15:00, 17:00, 19:00, and 23:00 h, during the same diel cycle. The temperature at the collection site was approximately $60^{\circ} \mathrm{C}$ in the main effluent channel. Channel water was filtered through $0.4 \mu \mathrm{m}$ HTTP Isopore ${ }^{\mathrm{TM}}$ polycarbonate membrane filters, collected in $160-\mathrm{mL}$ serum bottles, and then after several exchanges of the serum-bottle volume, sealed with butyl-acetate stoppers (without head-space).

\section{Metabolite Extraction}

A single metabolite extraction protocol was used for the analysis of the various classes of metabolites described herein. Frozen mats were thawed at room temperature and $100 \mu \mathrm{L}$ each of Nanopure $^{\mathrm{TM}}$ water and zirconia-silica beads $(0.1 \mathrm{~mm}$ size; Biospec Products; Bartlesville, OK) were added, respectively, to the samples and vigorously vortexed for $2 \mathrm{~min}$. This bead-beating process was repeated after the samples were maintained at room temperature for $5 \mathrm{~min}$. A mixture of chloroform/methanol $(400 \mu \mathrm{L}$; $2: 1, \mathrm{v} / \mathrm{v}$ ) spiked with $20 \mu \mathrm{g}$ of ${ }^{13} \mathrm{C}$-labeled acetate (Sigma-Aldrich catalog number 282022-250) was added to each disrupted mat sample, and the mixtures were repeatedly vortexed to ensure thorough mixing. The samples were centrifuged at 15,000 $\times g$ for $5 \mathrm{~min}$ at $4^{\circ} \mathrm{C}$ to separate aqueous and organic layers from precipitated proteins.

For analysis of acetate and propionate, aliquots $(50 \mu \mathrm{L})$ of the aqueous layer from each extract were transferred to glass vials equipped with glass inserts for direct GC-MS analysis without chemical derivatization. Because acetate and propionate are volatile molecules, all samples were immediately analyzed after extraction.

For untargeted analysis of polar metabolites, aliquots $(150 \mu \mathrm{L})$ of the remaining aqueous layer from each sample extract were transferred to glass vials and completely dried in vacuo. The dried extracts were stored at $-20^{\circ} \mathrm{C}$ until chemical derivatization.

For analysis of wax esters, aliquots $(200 \mu \mathrm{L})$ of the organic layer from each extract were analyzed directly using GC-MS without chemical derivatization.

For analysis of PHAs, the remaining organic layer from each extract was combined with the corresponding protein pellet, and the combined extract and pellet were completely dried in vacuo. The samples were hydrolyzed using a modification of the method reported by Lageveen et al. (1988). Briefly, the dried pellets were dissolved in methanol containing $15 \% \mathrm{H}_{2} \mathrm{SO}_{4}(\mathrm{v} / \mathrm{v})$ and incubated at $100^{\circ} \mathrm{C}$ for $15 \mathrm{~h}$. The resulting PHA monomers were extracted with chloroform and analyzed by GC-MS.

\section{Metabolomics Analyses}

An Agilent 7890A gas chromatograph coupled with a single quadrupole 5975C mass spectrometer (Agilent Technologies, Inc.) was used for all analyses. Samples were analyzed in duplicate by optimized GC-MS methods, which varied according to the classes of molecular targets as described below.

Acetate and propionate were quantified in a targeted fashion using ${ }^{13} \mathrm{C}$-labeled acetate as an internal standard. Briefly, mixtures of unlabeled acetate and proprionate at different concentrations were combined with constant amounts of ${ }^{13} \mathrm{C}$-labeled acetate in order to construct calibration curves. ${ }^{13} \mathrm{C}$-labeled acetate was then spiked into microbial mat lysates prior to extraction of metabolites, and the measured ratios of unlabeled acetate and propionate to labeled internal standard were used to accurately quantify the target molecules. A polar column (HP-FFAP; $30 \mathrm{~m} \times 0.250 \mathrm{~mm} \times 0.250 \mu \mathrm{m}$; Agilent Technologies, Santa Clara) was used. The temperature of the GC inlet was maintained at $200^{\circ} \mathrm{C}$, and samples $(1 \mu \mathrm{L})$ were injected in splitless mode with

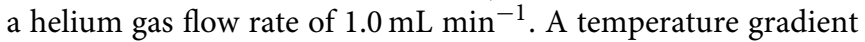
from 40 to $200^{\circ} \mathrm{C}$ over $20 \mathrm{~min}$ was used, and data were collected over the mass range $20-300 \mathrm{~m} / z$. To reduce any carry over arising from the direct injection of the aqueous layers (a mixture of methanol and water) from the metabolite extraction procedure, pure methanol blanks were analyzed between each sample.

For untargeted analysis of polar metabolites, extracted metabolites in the dried aqueous layers were chemically derivatized to trimethylsilyl esters as previously described (Kim et al., 2013). Metabolite extracts were dried in vacuo again to remove any residual moisture. To protect carbonyl groups and reduce the number of tautomeric isomers, methoxyamine $(20 \mu \mathrm{L}$ of a $30 \mathrm{mg} \mathrm{mL}^{-1}$ stock in pyridine) was added to each sample, followed by incubation at $37^{\circ} \mathrm{C}$ with shaking for $90 \mathrm{~min}$. To derivatize hydroxyl and amine groups to trimethylsilyated (TMS) 
forms, $N$-methyl- $N$-(trimethylsilyl)trifluoroacetamide (MSTFA) with $1 \%$ trimethylchlorosilane (TMCS) $(80 \mu \mathrm{L})$ was added to each vial, followed by incubation at $37^{\circ} \mathrm{C}$ with shaking for $30 \mathrm{~min}$. The samples were allowed to cool to room temperature and were analyzed on the same day. A HP-5MS column $(30 \mathrm{~m} \times 0.25 \mathrm{~mm}$ $\times 0.25 \mu \mathrm{m}$; Agilent Technologies) was used for untargeted analyses. Samples $(1 \mu \mathrm{L})$ were injected in splitless mode, and the helium gas flow rate was determined by the Agilent Retention Time Locking function based on analysis of deuterated myristic acid (Agilent Technologies, Santa Clara, CA). The injection port temperature was held at $250^{\circ} \mathrm{C}$ throughout the analysis. The $\mathrm{GC}$ oven was held at $60^{\circ} \mathrm{C}$ for $1 \mathrm{~min}$ after injection, and the temperature was then increased to $325^{\circ} \mathrm{C}$ by $10^{\circ} \mathrm{C} / \mathrm{min}$, followed by a $5 \mathrm{~min}$ hold at $325^{\circ} \mathrm{C}$. Data were collected over the mass range $50-550 \mathrm{~m} / z$. A mixture of FAMEs (C8-C28) was analyzed together with the samples for retention index alignment purposes during subsequent data analysis.

For analysis of wax esters, aliquots of the organic layer from the metabolite extracts were directly injected into the GC-MS. For analysis of PHA monomers, the acid-hydrolyzed samples were analyzed. Wax esters and PHA monomers were chromatographically separated using the same HP-5MS column as described above. Samples $(1 \mu \mathrm{L})$ were injected in splitless mode. The GC oven was held at $60^{\circ} \mathrm{C}$ for 5 (wax esters) or 10 (PHA monomers) min after injection, and the temperature was then increased to $325^{\circ} \mathrm{C}$ by $10^{\circ} \mathrm{C} / \mathrm{min}$, followed by a 1 (PHA monomers) or 5 (wax esters) min hold at $325^{\circ} \mathrm{C}$. The helium gas flow rate was $1.0 \mathrm{~mL} / \mathrm{min}$ and the injection port temperature was held at $250^{\circ} \mathrm{C}$ throughout the analysis. Data were collected over the mass range 50-600 (PHA monomers) or 50-700 (wax esters) $m / z$.

All GC-MS raw data will be made available via the MetaboLights metabolomics data repository (http://www.ebi.ac.uk/ metabolights/) under study identifier MTBLS187.

\section{Metabolomics Data Analysis}

The relative amounts of acetate and propionate in the mat samples were quantified by isotope dilution mass spectrometry. Standard curves for acetate and propionate were constructed as described above, and the integrated peak areas of acetate, propionate, and ${ }^{13} \mathrm{C}$-acetate in mat samples were determined using the corresponding extracted ion chromatograms (EICs; acetate, $\mathrm{m} / z$ 60 ; propionate, $\mathrm{m} / z 74$; and ${ }^{13} \mathrm{C}$-acetate, $\mathrm{m} / z$ 62). The peak areas of endogenous acetate and propionate were divided by that of ${ }^{13} \mathrm{C}$-acetate to obtain ratios of unlabeled/labeled target molecules.

GC-MS raw data files from untargeted analyses of polar metabolites were processed using MetaboliteDetector (Hiller et al., 2009). Retention indices (RI) of detected metabolites were calculated based on the analysis of the FAME standard mixture, followed by their chromatographic alignment across all analyses after deconvolution. Metabolites were then identified by matching GC-MS features (characterized by measured retention indices and mass spectra) to an augmented version of the Agilent Fiehn Metabolomics Retention Time Locked (RTL) Library (Kind et al., 2009), which contains spectra and validated retention indices for over 700 metabolites. All metabolite identifications were manually validated to reduce deconvolution errors during automated data-processing and to eliminate false identifications. The NIST 08 GC-MS library was also used to cross-validate the spectral matching scores obtained using the Agilent library. A heat-map analysis was also carried out after $z$-score transformation of the obtained signal intensities and with $\mathrm{K}$-means clustering $(K=5$, Distance metric: Euclidean) using DanteR (Taverner et al., 2012).

For wax ester analysis, the 10 most abundant species from $>30$ detected and quantified in the microbial mat samples were selected based on a previous report (Dobson et al., 1988), and their abundances were determined by the EIC method described above. For PHA analysis, the monomers were also quantified using the EIC method described above. A common representative fragment ion $(\mathrm{m} / z 103)$ was used for quantifying both 3-hydroxybutyrate and 3-hydroxyvalerate.

\section{Dissolved Gas Analysis}

Dissolved gasses $\left(\mathrm{CO}_{2}, \mathrm{H}_{2}\right.$, and $\left.\mathrm{CH}_{4}\right)$ were determined using closed head-space GC as described (Inskeep et al., 2005).

\section{Solar Irradiance Analysis}

The incident downwelling irradiance was logged throughout the field campaign with a LI-1400 light meter equipped with a LI-192 quantum irradiance sensor (LI-COR, Lincoln, NE).

\section{Results}

Triplicate samples were taken from a $60^{\circ} \mathrm{C}$ region of Mushroom Spring mat at approximately 2 -h intervals over a diel cycle (Figure 1). The top $5 \mathrm{~mm}$ was removed for solvent extraction and separate analyses of polar and volatile aqueous metabolites, PHAs and wax esters.

\section{Polar Metabolites in the Mat}

Untargeted metabolomics analyses were performed to identify fluctuations in polar metabolites. This analysis resulted in identification of 58 metabolites that were reproducibly detected in the 42 samples over the diel cycle. The time-course abundance patterns of these 58 metabolites are shown individually in Supplemental Figure S1. K-means clustering was used to categorize these patterns of temporal changes in relative abundances, resulting in five clusters of metabolites (Table 2) that each contained metabolites sharing similar patterns of abundance fluctuation over the diel cycle (Figure 2).

Metabolites detected in Cluster A accumulated in the predawn and early morning and included 3-hydroxybutyrate and 3hydroxyvalerate, the monomeric units of PHA. These two compounds showed similar patterns of relative abundance over the diel cycle, as well as to the monomers liberated from acid hydrolysis of intact PHA polymers (see below). Many of the metabolites of Cluster A were lowest in relative abundance in the afternoon and began to increase at 03:00 h, peaking by 09:00 to $11: 00 \mathrm{~h}$. Adenine, ornithine (indistinguished from arginine during GCMS analysis), dihydroxyacetone phosphate, $\alpha$-hydroxyglutaric acid, sophorose and phosphoinositol showed similar diel profiles.

Cluster B contains metabolites that showed highest abundances in late morning. These included the majority of the 
TABLE 2 | List of categorized metabolites showing diel cycling patterns.

\begin{tabular}{|c|c|c|}
\hline Cluster & Pattern ${ }^{a}$ & Metabolites \\
\hline A (8) & $\begin{array}{l}\text { Increase in early morning } \\
(03: 00-11: 00)\end{array}$ & $\begin{array}{l}\text { adenine } \\
\text { dihydroxyacetone phosphate } \\
\text { 3-hydroxybutyric acid } \\
\text { a-hydroxyglutaric acid } \\
\text { 3-hydroxyvaleric acid } \\
\text { L-ornithine } \\
\text { phosphoinositol } \\
\text { sophorose }\end{array}$ \\
\hline B (28) & $\begin{array}{l}\text { Increase in late morning } \\
(07: 00-11: 00)\end{array}$ & $\begin{array}{l}\text { L-asparagine } \\
\text { L-cysteine } \\
\text { fumaric acid } \\
\text { D-glucose } \\
\text { D-glucose-6-phsophate } \\
\text { L-glutamic acid } \\
\text { L-glutamine } \\
\text { glycine } \\
\text { hypoxanthine } \\
\text { inosine } \\
\text { lumazine } \\
\text { L-lysine } \\
\text { D-malic acid } \\
\text { maltose } \\
\text { maltotriose } \\
\text { methylcitric acid } \\
\text { nicotinic acid } \\
\text { L-phenylalanine } \\
\text { phosphate ion } \\
\text { L-pyroglutamic acid } \\
\text { ribose } \\
\text { L-serine } \\
\text { succinic acid } \\
\text { L-threonine } \\
\text { thymine } \\
\text { L-tyrosine } \\
\text { uracil } \\
\text { L-valine }\end{array}$ \\
\hline C (9) & $\begin{array}{l}\text { Increase in afternoon } \\
(11: 00-15: 30)\end{array}$ & $\begin{array}{l}\text { carbonate ion } \\
\text { citric acid } \\
\text { glyceric acid } \\
\text { glycolic acid } \\
\text { L-homoserine } \\
\text { oxalic acid } \\
\text { 2-oxo-glutaric acid } \\
\text { phosphoenolpyruvic acid } \\
\text { pyruvic acid }\end{array}$ \\
\hline $\mathrm{D}(11)$ & $\begin{array}{l}\text { Increase in late } \\
\text { afternoon/early evening } \\
(14: 30-22: 00)\end{array}$ & $\begin{array}{l}\text { adenosine } \\
\text { benzoic acid } \\
\text { glycerol-3-phosphate } \\
\text { L-(+) lactic acid } \\
\text { D-(+) melezitose } \\
\text { 1-methyl nicotinamide } \\
\text { 3-phosphoglyceric acid } \\
\text { pyrophosphate } \\
\text { D-(+) trehalose } \\
\text { urea } \\
\text { xylopyranose }\end{array}$ \\
\hline$E(2)$ & $\begin{array}{l}\text { Increase at night } \\
(19: 00-22: 00)\end{array}$ & $\begin{array}{l}\text { fructose } \\
\text { sucrose }\end{array}$ \\
\hline
\end{tabular}

${ }^{a}$ Clusters are the same as those shown in Figure 2. Numbers in parentheses correspond to the numbers of metabolites comprising the cluster.

"Metabolites identified by the NIST spectral library only. amino acids identified in the mat, precursors for the synthesis of nucleic acids, such as hypoxanthine, inosine, phosphoric acid, ribose, thymine, and uracil, as well as intermediates in glycolysis (e.g., glucose and glucose-6-phosphate) and the citric acid cycle (e.g., fumaric, malic, and succinic acids). The abundance profile of maltose, an $\alpha-1,4$ disaccharide of glucose, paralleled that of glucose, whereas maltotriose, an $\alpha-1,4$ trisaccharide of glucose, initially increased in abundance, gradually declined and then remained low with minor oscillations throughout the afternoon. A number of metabolites (e.g., asparagine, glycine, malic acid, phenylalanine, succinic acid, threonine, tyrosine, and valine) showed maximal abundances at 11:00 h, followed by an abrupt decrease near mid-day, which was then followed by a secondary maximum around 14:00-15:00 $\mathrm{h}$.

Metabolites assigned to Cluster $\mathrm{C}$ showed highest abundance in the early afternoon, a time that correlates to peak photosynthetic activity over the diel cycle (see Discussion). Organic acids such as citric, glyceric, glycolic, oxalic, 2-oxo-glutaric acid $(\alpha-$ ketoglutaric acid), and pyruvic acids were detected in highest abundance during the period of 12:00 to 16:00 h. In contrast to the proteinogenic amino acid serine, the abundance of homoserine was highest from 11:00 to 14:00 h, during which there was an abrupt decrease at mid-day.

Cluster D metabolites accumulated in the late afternoon. Among these, the amounts of lactate and urea dramatically increased from 12:30 to $15: 30 \mathrm{~h}$, then gradually decreased until mid-night. In contrast, benzoic acid, glycerol-3-phosphate and trehalose, an $\alpha, \alpha-1,1$ disaccharide of glucose, showed peak abundance in the early evening $(17: 00 \mathrm{~h})$.

Only two metabolites, fructose and sucrose, were assigned to cluster E; these accumulated around 19:00 to 22:00 h, decreased at $23: 00 \mathrm{~h}$, and then exhibited a relatively low but constant abundance from midnight to noon.

\section{Volatile Fatty Acids in the Mat}

To quantify acetate and propionate in the mat accurately, ${ }^{13} \mathrm{C}$ labeled acetate was spiked into samples as an internal standard before metabolite extraction, and the ratios of unlabeled acetate and propionate peak areas to ${ }^{13} \mathrm{C}$-acetate peak area were compared to a calibration curve. Using this quantitative approach, the levels of acetate and propionate were observed to be highest at midnight, followed by a gradual decrease to $17: 00 \mathrm{~h}$ (Figure 3). Overall, the abundances of acetate and propionate were similar to each other over the diel cycle.

\section{Carbon Storage Polymers in the Mat}

PHA was measured over the diel cycle in the form of the major components 3-hydroxybutyric acid (3-HB) and 3-hydroxyvaleric acid (3-HV) (Figure 4A). 3-HV was three times more abundant than 3-HB, with both fluctuating over the diel cycle, although the general trend was for accumulation from 19:00 to 10:00 h followed by a decrease between 10:00 and 19:00 h.

The mat contained a mixture of $\mathrm{C}_{30}-\mathrm{C}_{35} n, n$ and $i, n$ wax esters. In total, 42 species were identified (Supplemental Table S1), although we present data for the 10 most abundant species here (representative data shown in Figures 4B,C; all data shown in Supplemental Figure S2). The abundances of these wax esters 


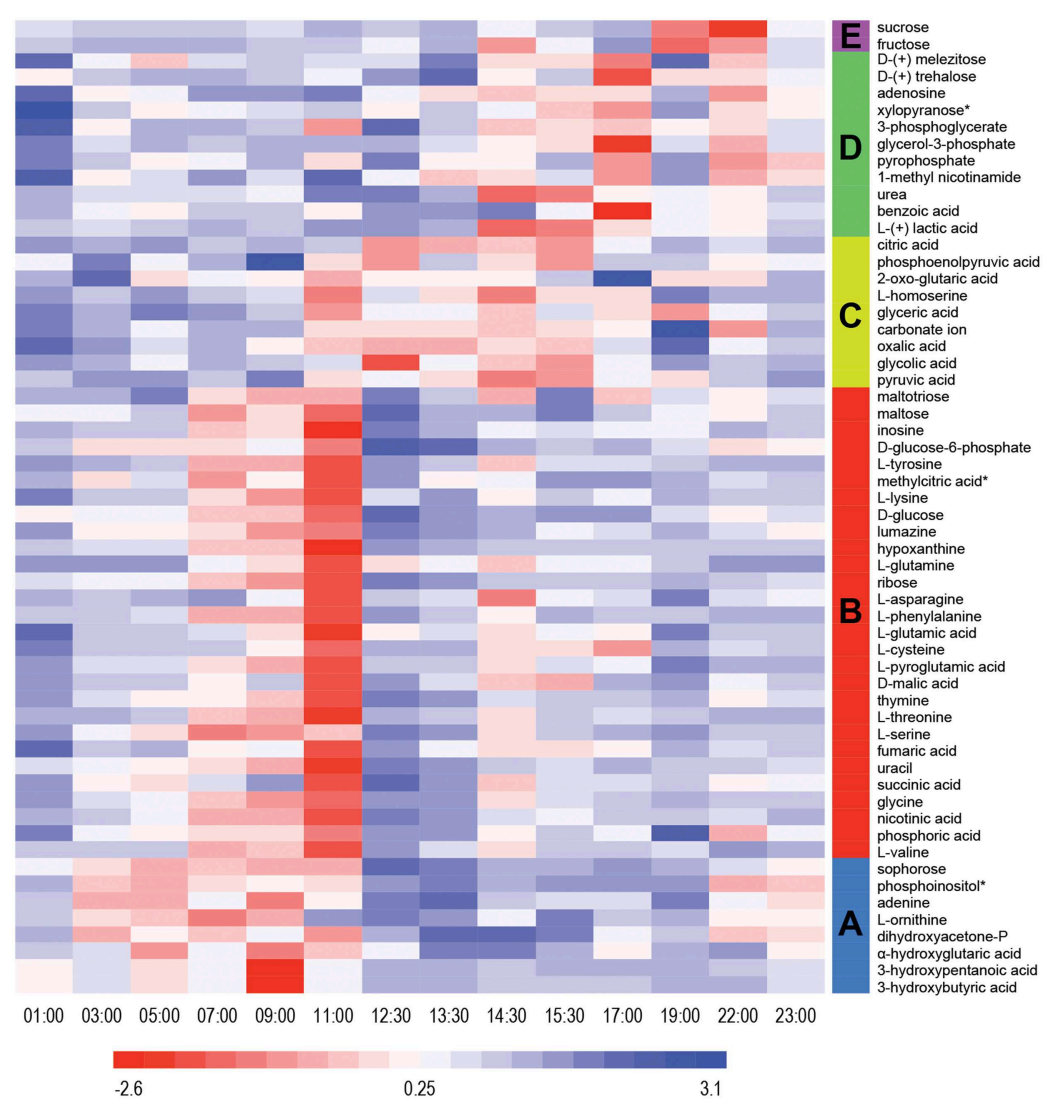

FIGURE 2 | Heat map view of z-scored polar metabolite abundances over a diel cycle. A total of 58 metabolites were reproducibly detected $(n=3)$ and confidently identified in the mat samples. The scale bar indicates the $z$-score transformed average intensity values of metabolites. K-means clustering was performed to categorize the metabolites based on their diel abundance patterns. Cluster A-increase in early morning; Cluster $\mathrm{B}$-increase in late morning; Cluster $\mathrm{C}$-increase in afternoon; Cluster D-increase in late afternoon/early evening; Cluster E-increase at night. changed throughout the diel cycle in a complex pattern. In general, the wax ester abundances showed decreases from mid-night to mid-day, except for increases in morning and afternoon, followed by an increase again in the evening. Interestingly, $i, n$ forms of $\mathrm{C}_{31}, \mathrm{C}_{32}$, and $\mathrm{C}_{35}$ wax esters increased before $n, n$ forms.

\section{Metabolite Partitioning in the Mat}

To evaluate the potential for metabolite exchange among members of the community, we analyzed additional mat core samples that were collected during four time points over the diel cycle and measured metabolites that were excreted or were otherwise extracellular. For this experiment, warm, filtered hot spring water was used to rinse the mat samples on site to avoid release of metabolites due to osmotic shock. Glycolate and lactate were the only metabolites confidently identified in the rinse waters within the detection limits of our instrumentation (data not shown). We compared the levels of these metabolites between the rinsed and control mats (Figures $5 \mathbf{A}, \mathbf{B}$ ) at 4 time points during the diel cycle. The highest level of glycolate in control and rinsed mat samples occurred at 13:00 h. Otherwise, the level of glycolate was relatively the same at 03:00, 09:00, and 19:00 h. In contrast, the abundance of lactate in the rinsed mat samples was equal across the four time points. The levels of lactate in the control mat were much higher than in the rinsed mat and increased from 03:00 to 19:00 h. Figure 5C shows data for glycolate and lactate over the full diel in unrinsed mat samples. The diel trends for glycolate in Figure 5A (control mat) and Figure 5C (unrinsed samples from the full diel sampling) clearly track each other. Similarly, the data for lactate in control mat from the rinsing experiment (Figure 5B) shows a rise in lactate abundance beginning at 13:00 h, which matches the time of the rise in lactate in the unrinsed samples from the full diel sample collection (Figure 5C). However, while the lactate abundance continues to rise to 19:00 h in the control mat from the rinsing experiment, it has begun to decline by $15: 30 \mathrm{~h}$ in the unrinsed samples from the full diel experiment.

\section{Gases in the Overflowing Water}

The amounts of three gaseous molecules in the water overflowing the $60^{\circ} \mathrm{C}$ mat- $\mathrm{CO}_{2}, \mathrm{H}_{2}$, and $\mathrm{CH}_{4}$-were also measured over the diel cycle (Figure 6). While the levels of hydrogen and carbon dioxide were lower during the day, methane abundance fluctuated, with maxima at 07:00, 12:30, and 23:00 h. 


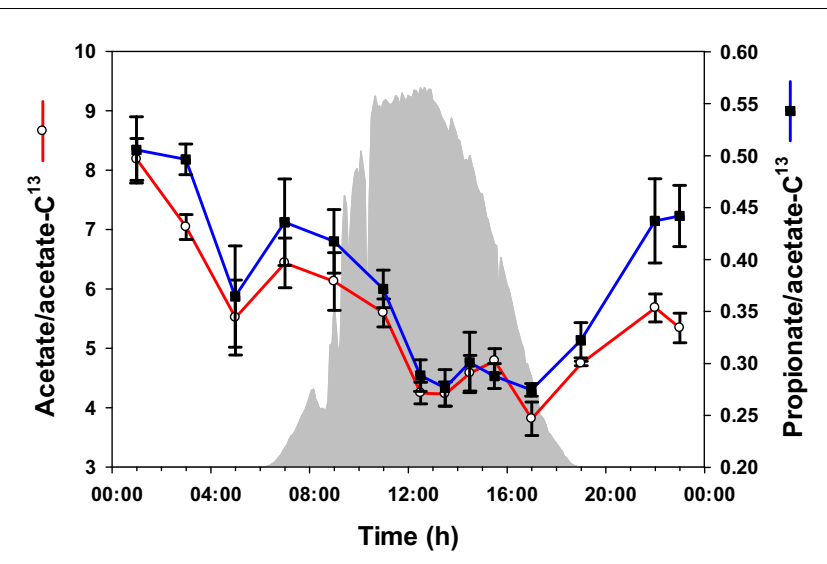

FIGURE 3 | Volatile metabolites over the diel cycle. Solar irradiance (solid gray) and acetate and propionate concentrations in unrinsed mat samples are shown. Metabolite values plotted are mean \pm standard error $(n=3)$.

\section{Discussion}

The application of systems biology approaches is expanding from lab-cultured samples to complex environmental communities. In this way, integrated studies are becoming more common for understanding biological systems through the combination of data from metagenomics, metatranscriptomics, metaproteomics, and metametabolomics analyses. Interpreting data from metabolomics analyses of a complex microbial community is challenging because many taxa may contribute to metabolite pools and because they may do so at different times during a diel cycle. Furthermore, metabolite concentrations represent pools that are influenced by production and consumption, as well as by diffusion, and all three factors are closely coupled in aquatic microbial mats. Thus, metabolite fluctuations with time likely represent periods of net production/accumulation or consumption/diffusion. Nevertheless, the data obtained in this study supported existing hypothesized metabolisms of major taxa in the mat and led to new hypotheses based on novel observations, as discussed below.

\section{Integration of Metabolomics and Gene Expression Data: Support of Existing Hypotheses on Synechococcus spp. and Roseiflexus spp. Metabolisms within the Mat Community}

In this section, we interpret certain metabolomics results in the context of hypotheses generated from previous diel metatranscriptomics studies (Liu et al., 2011, 2012; Klatt et al., 2013). Although the metatranscriptomics results are from a different year (September 2009), the long-term stability of the mat community, its composition and structure (Ramsing et al., 2000; Ferris et al., 2003; Ward et al., 2006; Becraft et al., 2011; Melendrez et al., 2011), processes conducted during diel cycles by phototrophic community members based on $\mathrm{O}_{2}$ concentration profiles, and expression of Synechococcus photosynthesis and $\mathrm{N}_{2}$ fixation genes (Ramsing et al., 2000; Ward et al., 2006; Steunou et al., 2008; Jensen et al., 2011; Liu et al., 2011, 2012) as measured between 1996 and the present, make comparisons of

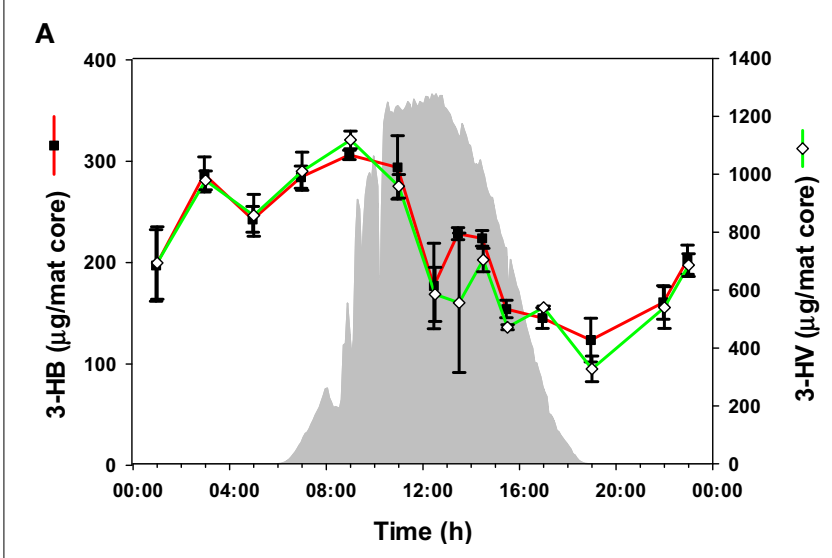

B

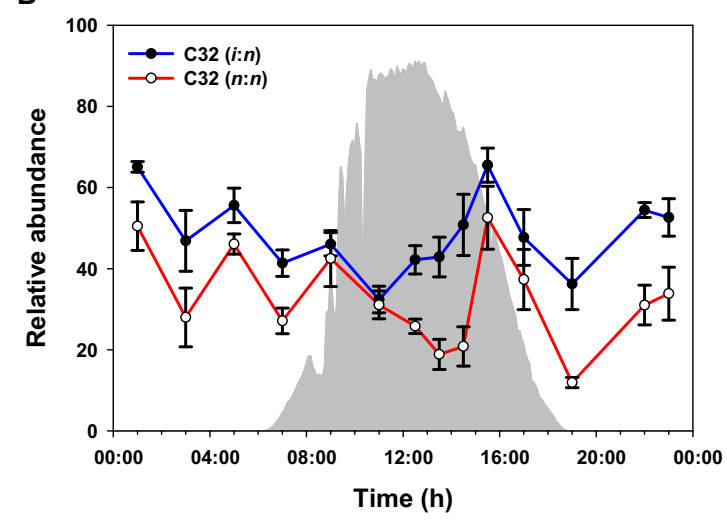

C

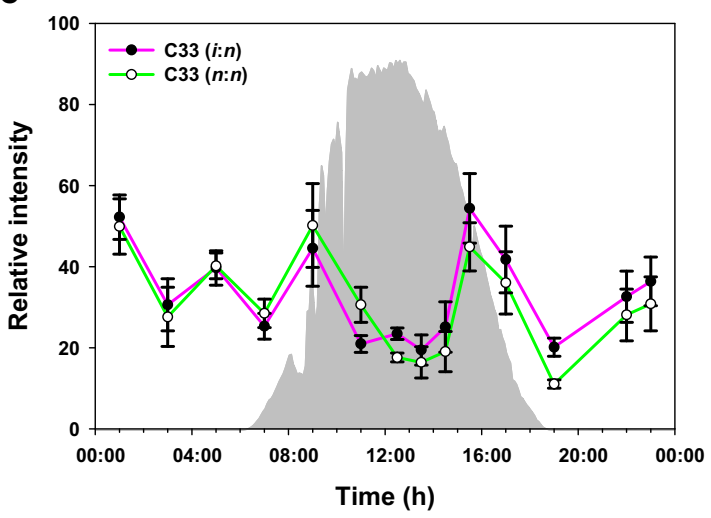

FIGURE 4 | PHAs and wax esters over the diel cycle. Solar irradiance (solid gray) and amount of monomers from hydrolysis of $\mathrm{PHAs}(\mathbf{A}) ; \mathrm{C}_{32}$ wax esters (B); $\mathrm{C}_{33}$ wax esters $(\mathbf{C})$. Metabolite values plotted are mean \pm standard error $(n=3)$.

data collected at comparable temperature sites and times of the year valid. Indeed, comparison of solar irradiance and glycolate levels over a diel cycle in mat samples collected in 2011 showed very similar abundance profiles as the data presented here (Supplemental Figure S3).

\section{Synechococcus spp.}

Based on diel changes in glycogen (Van Der Meer et al., 2007) and metatranscriptomics analyses (Liu et al., 2012), we 

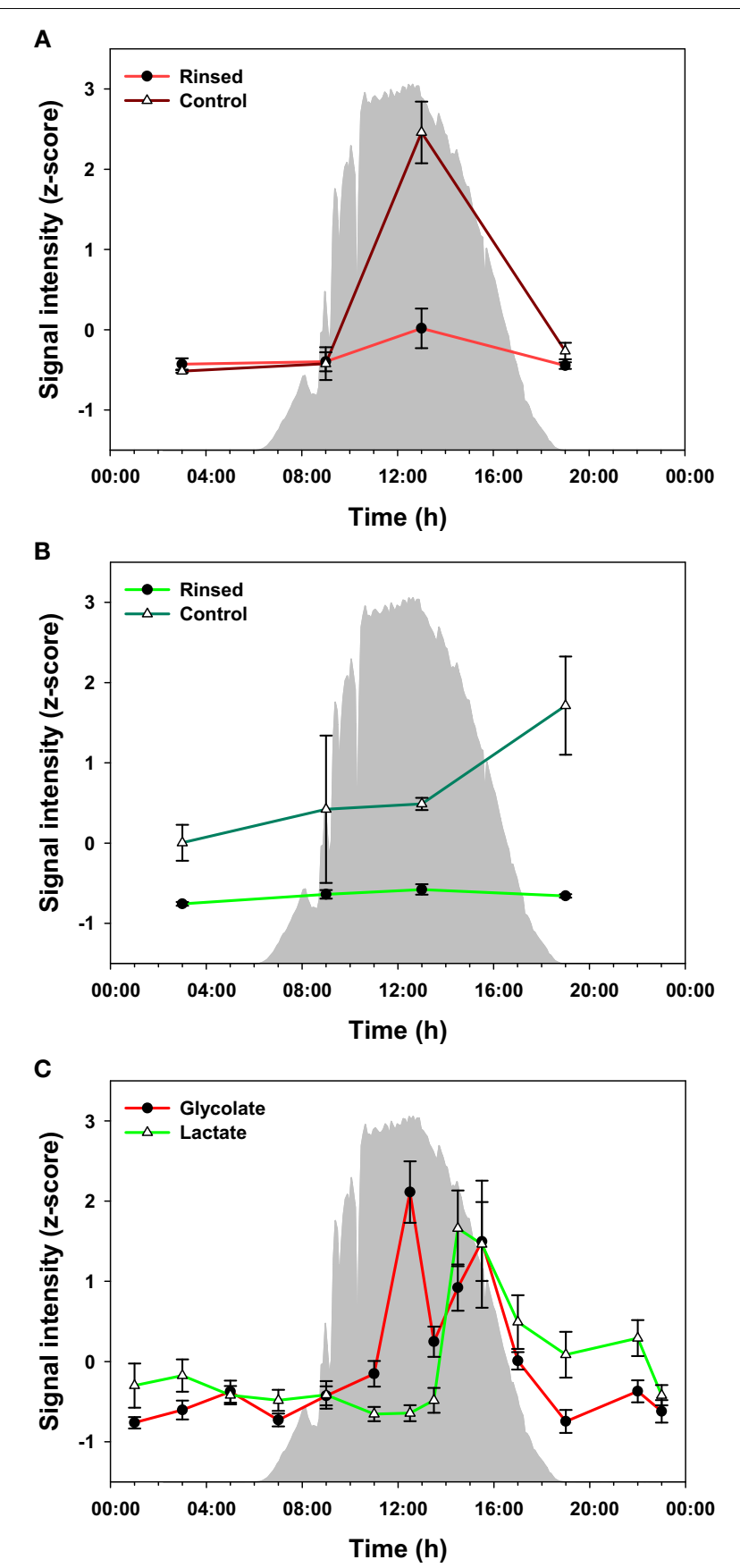

FIGURE 5 | Measured levels of glycolate (A) and lactate (B) from the rinsed and control (un-rinsed) mats. The difference between the two conditions is regarded as a portion biologically available by excretion and diffusion in the mats, which can be taken up by other heterotrophic bacteria in the communities. Glycolate and lactate profiles in the unrinsed mat over the full diel cycle (C) are shown as a reference. The glycolate and lactate abundances were $z$-score transformed (i.e., normalized), and the values plotted are mean \pm standard error $(n=3)$. Solar irradiance is shown in solid gray.

hypothesized that Synechococcus spp. shift from daytime photosynthesis and the production of glycogen to nighttime glycogen fermentation (Van Der Meer et al., 2007). Consistent with

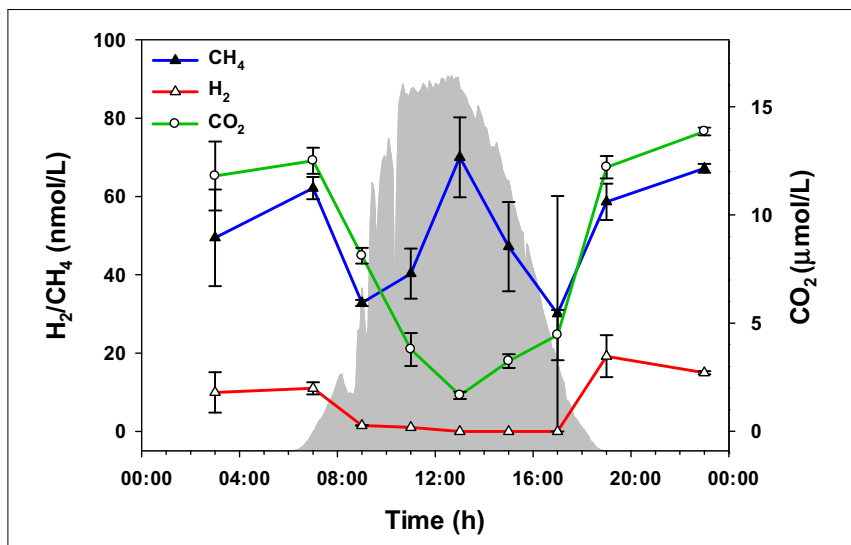

FIGURE 6 | Gaseous metabolites over the diel cycle. Solar irradiance (solid gray) and $\mathrm{CO}_{2}, \mathrm{H}_{2}$, and $\mathrm{CH}_{4}$ levels in water overflowing the mat are shown. Metabolite values plotted are mean \pm standard error $(n=3)$.

this hypothesis, fermentation products that mat Synechococcus populations have the genetic potential to produce (e.g., acetate and lactate) accumulated during the afternoon and night (Figures 3, 5C).

Mid-day extremes of light and $\mathrm{O}_{2}$ concentration, as well as $\mathrm{CO}_{2}$ depletion (suggested by a rise in $\mathrm{pH}$, which shifts the carbonate equilibrium) have been shown to lead to photorespiratory production of glycolate (Bateson and Ward, 1988). Thus, we hypothesized that Synechococcus spp. in the mat experience photorespiration during periods of high light irradiance. Supporting this hypothesis, $\mathrm{CO}_{2}$ in the water flowing over the mat decreased during the day (Figure 6), and glycolate accumulated between $\sim 12: 00$ and $\sim 16: 00 \mathrm{~h}$ (Figure 5C). Production of glycolate at peak solar irradiance correlated with the expression of Synechococcus spp. genes encoding photosynthesis machinery (Liu et al., 2012).

Additionally, nighttime and early morning $\mathrm{N}_{2}$ fixation by Synechococcus has been demonstrated (Steunou et al., 2006, 2008), and because mat Synechococcus lack an uptake hydrogenase, we hypothesized that $\mathrm{H}_{2}$ accumulation should temporally follow $\mathrm{N}_{2}$ fixation. Diel patterns of $\mathrm{H}_{2}$ concentration in the water above the mat (Figure 6) are consistent with this prediction.

\section{Roseiflexus spp.}

Noting the diel cycling of transcript abundances encoding enzymes associated with the 3-hydroxypropionate pathway and the production and consumption of polymers known to be produced by Roseiflexus spp., Klatt et al. (2013) hypothesized that Roseiflexus spp. shift from a photomixotrophic metabolism leading to glycogen synthesis during the day to nighttime fermentation of glycogen, coupled with nighttime synthesis of PHA and/or wax esters, whose breakdown during the day could in turn provide the necessary metabolites for photomixotrophy. Consistent with this hypothesis, diel glycogen cycling was previously demonstrated by Van Der Meer et al. (2007). Also consistent with the hypothesis, levels of $\mathrm{CO}_{2}$ in the water overflowing the mat and of intracellular fermentation products known to be used by Roseiflexus [e.g., acetate, propionate, and lactate; based 
on genomic (Van Der Meer et al., 2010; Bryant et al., 2012) and metagenomic (Klatt et al., 2011) analyses and on laboratory growth experiments (Hanada et al., 2002)] are lower during the day.

In addition, PHAs, measured by their constituent monomers (e.g., 3-HB and 3-HV) after acid hydrolysis of the polymers, were relatively higher at night and in the early morning, followed by a decrease during the day (Figure 4A). The accumulation of $3-\mathrm{HB}$ and $3-\mathrm{HV}$ as free monomers in the morning (Figure 2, Supplemental Figure S1), together with methyl-citrate, an intermediate in the oxidation of propionate (which could be derived from 3-HV), provides evidence that PHAs are being degraded in the early morning. These observations are consistent with previous metatranscriptomics data on expression of Roseiflexus spp. PHA biosynthesis genes, and our previous hypothesis that these molecules might be used for mixotrophic metabolism by filamentous anoxygenic phototrophic bacteria (Klatt et al., 2013).

Wax esters generally cycled in a manner consistent with the expression patterns of Roseiflexus genes associated with their production and degradation, supporting their hypothesized involvement in photomixotrophy. However, these compounds fluctuated in a complex manner, possibly reflecting differences due to the timing of metabolisms of different Roseiflexus species (see below).

\section{Novel Observations Leading to New Hypotheses}

In this section, we highlight novel observations of metabolism in the Mushroom Spring microbial mat community with respect to metabolites identified or measured for the first time, as well as to the time of day at which certain metabolites showed peaks in accumulation. These observations were then used as the basis upon which new hypotheses have been formulated.

\section{Detection and Accumulation of Previously Unreported Metabolites}

The accumulation of $\mathrm{CH}_{4}$ in the mat at mid-day was unexpected (Figure 6), since methanogenesis is an anaerobic process that should only occur in the anoxic nighttime mat (Ward, 1978; Sandbeck and Ward, 1981). However, genomic and metagenomic analyses indicate that Synechococcus spp. have the potential to metabolize phosphonate (Gomez-Garcia et al., 2011), which can also lead to methane production. We therefore hypothesize that the mid-day peak in methane concentration is a result of Synechococcus spp. metabolism of phosphonates.

Metabolites in cluster B accumulated specifically in the morning and in general reached their highest levels at 11:00 h. The metabolites present in this cluster (most amino acids, hypoxanthine, inosine, phosphoric acid, ribose, thymine, and uracil) imply that amino and nucleic acid biosynthesis occur maximally during the early morning period. Interestingly, all of these nitrogen-rich compounds reached peak levels shortly after the maximal period of $\mathrm{N}_{2}$ fixation by Synechococcus spp., which occurred between 06:00 and 10:00 h in the morning (Steunou et al., 2008). This period also corresponded to the time when total mRNA levels increased sharply in members of the major phototrophic taxa that occur in the mats Liu et al., 2011, 2012; Klatt et al., 2013). While not unexpected, these collective observations lead to the hypothesis that the morning hours represent a time when RNA, DNA, and protein biosynthesis rates are maximal for major taxa in the mat.

At midday (11:00 to $12: 00 \mathrm{~h}$ ) there is an abrupt decline in all metabolites of cluster $B$, when metabolites of cluster $C$, including glycolate, oxalate, carbonate, citrate, and phosphoenolpyruvate, accumulated (Figure 2). The accumulation of glycolate (as discussed above), glycerate, and oxalate is likely due to photorespiration by Synechococcus spp. (Bateson and Ward, 1988; Bauwe et al., 2010). Interestingly, the abundance of carbonate ion also increased at this time, consistent with extreme $\mathrm{CO}_{2}$ consumption and elevated $\mathrm{pH}$ during peak periods of photosynthesis shifting the equilibrium of dissolved inorganic carbon (Revsbech and Ward, 1984; Jensen et al., 2011). Also of interest is the observation that peak production of glycolate coincides with the abrupt decrease in levels of certain metabolites (asparagine, glycine, malic acid, phenylalanine, succinic acid, threonine, tyrosine, and valine) in cluster $B$, suggesting a decrease in activity in these metabolic pathways possibly due to photoinhibition. At the same time as the abrupt decrease in abundances of cluster B metabolites and just after the peak in glycolate abundance $(\sim 12: 00 \mathrm{~h})$, the levels of lactate in the mat begin to increase, with maximal abundance at $\sim 15: 00 \mathrm{~h}$ and correlating with a second peak in glycolate abundance (Figure 5C). We hypothesize that Synechococcus spp. may be a source of the peak in lactate abundance at this time via fermentation either as an alternative metabolism for photoinhibited cells closest to the mat surface, or because cells deeper in the mat experience a shorter period of peak solar irradiance (Becraft et al., this issue; Olsen et al., this issue), or both.

\section{Metabolite Exchange}

Metabolic interactions among community members are key features stabilizing the composition and function of microbial communities. In a chlorophototrophic microbial community, organic compounds produced and excreted by $\mathrm{CO}_{2}$-fixing taxa could be used as nutrients by (photo)-heterotrophic or mixotrophic mat community members. Indeed, diurnal transcription patterns of the genes involved in $\mathrm{CO}_{2}$ fixation have suggested that Roseiflexus spp. in the Mushroom Spring mat community can conduct photomixotrophic metabolism, presumably using organic compounds produced and excreted by other community members. In this section, we discuss the potential for metabolic exchange between Synechococcus and Roseiflexus spp.

Two metabolites, the photorespiration product glycolate and the fermentation product lactate, were identified in the extracellular fractions of the rinsing experiment and were therefore available as nutrients for members of the mat community. Glycolate was most abundant in the mat during the early afternoon (Figures 2, 5C, and Supplemental Figure S1). At 13:00 h, the amount of glycolate associated with mat biomass was much lower $(25-30 \%)$ in the rinsed compared to the unrinsed control samples, suggesting that glycolate is excreted into the intracellular milieu (Figure 5A). At other time points examined, the amounts of glycolate were similar in rinsed or unrinsed samples, suggesting a balanced consumption and production or 
that photorespiration is less active at lower irradiance levels. Although, Klatt et al. (2013) did not observe significant changes in transcription patterns in Roseiflexus spp. during the same time period as the peak in mat glycolate abundance, these organisms are still the most likely consumers of glycolate because glyoxylate derived from glycolate by oxidation can readily be assimilated by the 3-hydroxypropionate bi-cycle (Klatt et al., 2007). In contrast, a very sharp and large increase $(\sim 60$-fold above the minimum) in transcript abundance for lactate permease in Roseiflexus sp. at approximately 18:00 h has been observed (Bryant et al., unpublished data), just after the afternoon increase in lactate abundance in unrinsed vs. rinsed mat samples in our experiment (Figure 5B). This observation suggests that Roseiflexus sp. might utilize a significant proportion of the lactate produced. Indeed, lactate levels declined in the early evening hours after the spike in lactate permease transcripts occurred. As with glycolate, the lower levels of lactate during the night may indicate an efficient balance between production and consumption. Based on these observations, we hypothesize that glycolate, and possibly lactate (as discussed above), are mostly produced and excreted by the cyanobacteria (i.e., Synechococcus spp.) during the early afternoon and are available to other mat inhabitants, particularly Roseiflexus spp., as a carbon and energy source.

It is interesting that only glycolate and lactate were identified in the rinse water. We have considered several possible explanations for this observation. It is possible that other extracellular metabolites (e.g., volatile fatty acids, ethanol) may have been lost during the in vacuo drying of the rinse water samples, as previous analyses have shown that these compounds accumulate in the aqueous fraction during dark, anaerobic incubation of mat samples (Anderson et al., 1987). Alternatively, our sampling of extracellular metabolites, which occurred at 03:00, 09:00, 13:00, and 19:00 h, may not have occurred during the peak times of metabolite excretion. A third possibility is that certain metabolites are rapidly scavenged from the extracellular milieu as soon as they are excreted. The last possibility is that there were no other metabolites that were excreted.

\section{Depth- or Temporally-Resolved Metabolisms}

As mentioned above, a complex pattern of wax ester abundances was observed, with peak abundances in the predawn, morning, and afternoon periods, and differential timing of $i, n$ and $n, n$-forms of the same wax esters. Such complexity might arise because of contributions from multiple taxa capable of wax ester synthesis with different diel timing. As shown in Table 3, although Roseiflexus wax esters are a better match to wax esters found in the mat, Chloroflexus also makes $n, n$ forms of $\mathrm{C}_{31}$, $\mathrm{C}_{32}$, and $\mathrm{C}_{35}$ wax esters, and the different abundances of these forms might relate to differential timing of wax ester synthesis in members of these two genera. Such could also be the case for different Roseiflexus species. Zeng et al. (1992) showed that the ratio of $i, n$ - to $n, n$-forms of $\mathrm{C}_{31-35}$ wax esters increased nearly 5-fold in mat layers 4-5 mm below the surface of the highly similar Octopus Spring mat, raising the question of whether different species of Roseiflexus, with different vertical distributions, experience different light regimes and have different timing of wax ester synthesis and degradation. Taxon-related and/or depthrelated differences in metabolisms may be generally important, because similar small-scale fluctuations were observed in PHA, glycolate, and fermentation products. Furthermore, a number of metabolites (e.g., asparagine, glycine, malic acid, phenylalanine, succinic acid, threonine, tyrosine, and valine) showed maxima in abundances at 11:00 h, followed by an abrupt decrease near mid-day, which was then followed by a secondary maximum around 14:00-15:00 h. Metabolomics analyses were conducted on the top $5 \mathrm{~mm}$ region of the mat, whereas the transcription results of Klatt et al. (2013) were from the top $2 \mathrm{~mm}$ region. Different taxa (and/or different species within these taxa) inhabit different vertical regions of the mat (Ramsing et al., 2000; Becraft et al., 2011), and we hypothesize that they exhibit maximal metabolic rates for specific processes at different times during the diel cycle.

TABLE 3 | Wax ester content of mat and Chloroflexi and timing of abundance changes in the mat.

\begin{tabular}{|c|c|c|c|c|c|c|c|c|}
\hline Wax ester & Roseiflexus $^{\mathrm{a}}$ & Chloroflexus $^{\mathrm{a}}$ & mat $^{a}$ & Evening rise start & Night peak & Morning peak & Afternoon rise start & Afternoon peak \\
\hline C31 $n, n$ & + & & ++ & $19: 00$ & 01:00 & 05:00 & $14: 30$ & $15: 30$ \\
\hline C31 i,n & + & & + & $17: 00$ & $22: 00$ & 03:00 & $11: 30$ & $14: 30$ \\
\hline C32 n,n & ++ & + & +++ & 19:00 & 01:00 & 05:00, 09:00 & $14: 30$ & $15: 30$ \\
\hline C32 i,n & +++ & & ++ & $19: 00$ & 01:00 & 05:00, 09:00 & $12: 30$ & $15: 30$ \\
\hline C33 $n, n$ & + & + & +++ & $19: 00$ & 01:00 & 05:00, 09:00 & $14: 30$ & $15: 30$ \\
\hline C33 i,n & + & & ++ & 19:00 & 01:00 & 05:00, 09:00 & $14: 30$ & $15: 30$ \\
\hline C34 $n, n$ & +++ & ++ & ++ & $19: 00$ & 01:00 & 05:00, 09:00 & $13: 30$ & $15: 30$ \\
\hline C34 i,n & +++ & & + & 19:00 & 01:00 & 05:00, 09:00 & $13: 30$ & $15: 30$ \\
\hline C35 n,n & + & ++ & + & 19:00 & 01:00 & 05:00, 09:00 & $15: 00$ & $17: 00$ \\
\hline C35 i,n & + & & + & $19: 00$ & 01:00 & 05:00, 09:00 & 13:00 & $17: 00$ \\
\hline C36 n,n & & ++ & & & & & & \\
\hline C37 n,n & & + & & & & & & \\
\hline
\end{tabular}

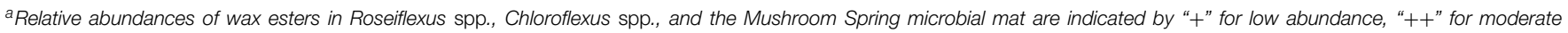
abundance, and "+ + +" for high abundance. Data for Roseiflexus spp. and Chloroflexus spp. are from Van Der Meer et al. (2010). 
Indeed, evidence that Synechococcus species with different depth distributions (Becraft et al., this issue), light adaptations (Nowack et al., this issue) and gene expression timing (Olsen et al., this issue), strongly supports this hypothesis.

\section{Acknowledgments}

We thank Prof. Alexander Steinbüchel at the University of Münster for kindly providing purified PHA polymers and William P. Inskeep and members of his lab for lending equipment and providing instructions for water chemistry analyses. This research was supported by the Genomic Science Program (GSP), Office of Biological and Environmental Research (OBER), U.S. Department of Energy (DOE), and is a contribution of the Pacific Northwest National Laboratory (PNNL) Foundational Scientific Focus Area. We also acknowledge funding provided for this project by NSF-DMS 1022836 and the Montana Space Grant Consortium. DMW appreciates support from

\section{References}

Anderson, K. L., Tayne, T. A., and Ward, D. M. (1987). Formation and fate of fermentation products in hot spring cyanobacterial mats. Appl. Environ. Microbiol. 53, 2343-2352.

Bateson, M. M., and Ward, D. M. (1988). Photoexcretion and fate of glycolate in a hot spring cyanobacterial mat. Appl. Environ. Microbiol. 54, 1738-1743.

Bauld, J., and Brock, T. (1973). Ecological studies of Chloroflexis, a gliding photosynthetic bacterium. Arch. Mikrobiol. 92, 267-284. doi: 10.1007/BF00 409281

Bauwe, H., Hagemann, M., and Fernie, A. R. (2010). Photorespiration: players, partners and origin. Trends Plant Sci. 15, 330-336. doi: 10.1016/j.tplants.2010.03.006

Becraft, E. D., Cohan, F. M., Kühl, M., Jensen, S. I., and Ward, D. M. (2011). Fine-Scale distribution patterns of Synechococcus ecological diversity in microbial mats of Mushroom Spring, Yellowstone National Park. Appl. Environ. Microbiol. 77, 7689-7697. doi: 10.1128/AEM.05927-11

Bhaya, D., Grossman, A. R., Steunou, A.-S., Khuri, N., Cohan, F. M., Hamamura, N., et al. (2007). Population level functional diversity in a microbial community revealed by comparative genomic and metagenomic analyses. ISME J. 1, 703-713. doi: 10.1038/ismej.2007.46

Brock, T. D. (1972). “One hundred years of algal research in Yellowstone National Park," in Proceedings of the International Symposium on Taxonomy and Biology of Blue-Green Algae, ed T. V. Desikachary (Madras), 393-405.

Brock, T. D. (1978). Thermophilic Microorganisms and Life at High Temperatures. New York, NY: Springer-Verlag. doi: 10.1007/978-1-4612-6284-8

Brock, T. D. (1998). Early days in Yellowstone microbiology. ASM News 64, 137-140.

Bryant, D. A., Costas, A. M. G., Maresca, J. A., Chew, A. G. M., Klatt, C. G., Bateson, M. M., et al. (2007). Candidatus Chloracidobacterium thermophilum: an aerobic phototrophic acidobacterium. Science 317, 523-526. doi: 10.1126/science. 1143236

Bryant, D. A., Liu, Z., Li, T., Zhao, F., Garcia Costas, A. M., Klatt, C. G., et al. (2012). "Comparative and functional genomics of anoxygenic green bacteria from the taxa Chlorobi, Chloroflexi, and Acidobacteria," in Advances in Photosynthesis and Respiration: Functional Genomics and Evolution of Photosynthetic Systems, eds R. L. Burnap and W. Vermaas (Dordrecht: Springer), 47-102.

Dobson, G., Ward, D. M., Robinson, N., and Eglinton, G. (1988). Biogeochemistry of hot spring environments: extractable lipids of a cyanobacterial mat. Chem. Geol. 68, 155-179. doi: 10.1016/0009-2541(88)90093-9

Ferris, M. J., Kühl, M., Wieland, A., and Ward, D. M. (2003). Cyanobacterial ecotypes in different optical microenvironments of a $68^{\circ} \mathrm{C}$ hot spring mat community revealed by $16 \mathrm{~S}-23 \mathrm{~S}$ rRNA internal transcribed spacer region variation. the Montana Agricultural Experiment Station (project 911352). $\mathrm{DAB}$ acknowledges funding from the Division of Chemical Sciences, Geosciences, and Biosciences, Office of Basic Energy Sciences of the DOE through Grant DE-FG02-94ER20137. Portions of this research were enabled by capabilities developed by the PNNL Pan-omics Program under support from the DOE OBER GSP. Metabolite measurements were performed in the Environmental Molecular Sciences Laboratory, a national scientific user facility sponsored by OBER and located at PNNL. PNNL is a multi-program national laboratory operated by Battelle for the DOE under Contract DE-AC05-76RLO 1830 .

\section{Supplementary Material}

The Supplementary Material for this article can be found online at: http://www.frontiersin.org/journal/10.3389/fmicb. 2015.00209/abstract

Appl. Environ. Microbiol. 69, 2893-2898. doi: 10.1128/AEM.69.5.28932898.2003

Garcia Costas, A. M., Tsukatani, Y., Rijpstra, W. I. C., Schouten, S., Welander, P. V., Summons, R. E., et al. (2012). Identification of the bacteriochlorophylls, carotenoids, quinones, lipids, and hopanoids of "Candidatus Chloracidobacterium thermophilum.” J. Bacteriol. 194, 1158-1168. doi: 10.1128/JB. 06421-11

Gomez-Garcia, M. R., Davison, M., Blain-Hartnung, M., Grossman, A. R., and Bhaya, D. (2011). Alternative pathways for phosphonate metabolism in thermophilic cyanobacteria from microbial mats. ISME J. 5, 141-149. doi: 10.1038/ismej.2010.96

Hanada, S., Takaichi, S., Matsuura, K., and Nakamura, K. (2002). Roseiflexus castenholzii gen. nov., sp. nov., a thermophilic, filamentous, photosynthetic bacterium that lacks chlorosomes. Int. J. Syst. Evol. Microbiol. 52, 187-193.

Hiller, K., Hangebrauk, J., JäGer, C., Spura, J., Schreiber, K., and Schomburg, D. (2009). MetaboliteDetector: comprehensive analysis tool for targeted and nontargeted GC/MS based metabolome analysis. Anal. Chem. 81, 3429-3439. doi: $10.1021 / \mathrm{ac} 802689 \mathrm{c}$

Inskeep, W. P., Ackerman, G. G., Taylor, W. P., Kozubal, M., Korf, S., and Macur, R. E. (2005). On the energetics of chemolithotrophy in nonequilibrium systems: case studies of geothermal springs in Yellowstone National Park. Geobiology 3, 297-317. doi: 10.1111/j.1472-4669.2006.00059.x

Jensen, S. I., Steunou, A.-S., Bhaya, D., Kuhl, M., and Grossman, A. R. (2011). In situ dynamics of $\mathrm{O}_{2}, \mathrm{pH}$ and cyanobacterial transcripts associated with CCM, photosynthesis and detoxification of ROS. ISME J. 5, 317-328. doi: 10.1038/ismej.2010.131

Kim, Y.-M., Schmidt, B. J., Kidwai, A. S., Jones, M. B., Kaiser, B. L. D., Brewer, H. M., et al. (2013). Salmonella modulates metabolism during growth under conditions that induce expression of virulence genes. Mol. Biosyst. 9, 1522-1534. doi: $10.1039 / \mathrm{c} 3 \mathrm{mb} 25598 \mathrm{k}$

Kind, T., Wohlgemuth, G., Lee, D. Y., Lu, Y., Palazoglu, M., Shahbaz, S., et al. (2009). FiehnLib: mass spectral and retention index libraries for metabolomics based on quadrupole and time-of-flight gas chromatography/mass spectrometry. Anal. Chem. 81, 10038-10048. doi: 10.1021/ac9019522

Klatt, C. G., Bryant, D. A., and Ward, D. M. (2007). Comparative genomics provides evidence for the 3-hydroxypropionate autotrophic pathway in filamentous anoxygenic phototrophic bacteria and in hot spring microbial mats. Environ. Microbiol. 9, 2067-2078. doi: 10.1111/j.1462-2920.2007. 01323.x

Klatt, C. G., Liu, Z., Ludwig, M., Kuhl, M., Jensen, S. I., Bryant, D. A., et al (2013). Temporal metatranscriptomic patterning in phototrophic Chloroflexi inhabiting a microbial mat in a geothermal spring. ISME J. 7, 1775-1789. doi: 10.1038/ismej.2013.52 
Klatt, C. G., Wood, J. M., Rusch, D. B., Bateson, M. M., Hamamura, N., Heidelberg, J. F., et al. (2011). Community ecology of hot spring cyanobacterial mats: predominant populations and their functional potential. ISME J. 5, 1262-1278. doi: 10.1038/ismej.2011.73

Koek, M., Jellema, R., Greef, J., Tas, A., and Hankemeier, T. (2011). Quantitative metabolomics based on gas chromatography mass spectrometry: status and perspectives. Metabolomics 7, 307-328. doi: 10.1007/s11306-010-0254-3

Konopka, A. (1992). Accumulation and utilization of polysaccharide by hot-spring phototrophs during a light-dark transition. FEMS Microbiol. Lett. 102, 27-32. doi: 10.1111/j.1574-6968.1992.tb05792.x

Lageveen, R. G., Huisman, G. W., Preusting, H., Ketelaar, P., Eggink, G., and Witholt, B. (1988). Formation of polyesters by Pseudomonas oleovorans: effect of substrates on formation and composition of poly-(R)-3-hydroxyalkanoates and poly-(R)-3-hydroxyalkenoates. Appl. Environ. Microbiol. 54, 2924-2932.

Liu, Z., Klatt, C. G., Ludwig, M., Rusch, D. B., Jensen, S. I., Kuhl, M., et al. (2012). 'Candidatus Thermochlorobacter aerophilum:' an aerobic chlorophotoheterotrophic member of the phylum Chlorobi defined by metagenomics and metatranscriptomics. ISME J. 6, 1869-1882. doi: 10.1038/ismej.2012.24

Liu, Z., Klatt, C. G., Wood, J. M., Rusch, D. B., Ludwig, M., Wittekindt, N., et al. (2011). Metatranscriptomic analyses of chlorophototrophs of a hot-spring microbial mat. ISME J. 5, 1279-1290. doi: 10.1038/ismej.2011.37

Madigan, M. T., and Brock, T. D. (1975). Photosynthetic sulfide oxidation by Chloroflexus aurantiacus, a filamentous, photosynthetic, gliding bacterium. J. Bacteriol. 122, 782-784.

Melendrez, M. C., Lange, R. K., Cohan, F. M., and Ward, D. M. (2011). Influence of molecular resolution on sequence-based discovery of ecological diversity among Synechococcus populations in an alkaline siliceous hot spring microbial mat. Appl. Environ. Microbiol. 77, 1359-1367. doi: 10.1128/AEM.02032-10

Mosier, A. C., Justice, N. B., Bowen, B. P., Baran, R., Thomas, B. C., Northen, T. R., et al. (2013). Metabolites associated with adaptation of microorganisms to an acidophilic, metal-rich environment identified by stableisotope-enabled metabolomics. MBio 4, e00484-e00412. doi: 10.1128/mBio. 00484-12

Nold, S. C., and Ward, D. M. (1996). Photosynthate partitioning and fermentation in hot spring microbial mat communities. Appl. Environ. Microbiol. 62, 4598-4607.

Papke, R. T., Ramsing, N. B., Bateson, M. M., and Ward, D. M. (2003). Geographical isolation in hot spring cyanobacteria. Environ. Microbiol. 5, 650-659. doi: 10.1046/j.1462-2920.2003.00460.x

Ramsing, N. B., Ferris, M. J., and Ward, D. M. (2000). Highly ordered vertical structure of Synechococcus populations within the one-millimeter-thick photic zone of a hot spring cyanobacterial mat. Appl. Environ. Microbiol. 66, 1038-1049. doi: 10.1128/AEM.66.3.1038-1049.2000

Revsbech, N. P., and Ward, D. M. (1984). Microelectrode studies of interstitial water chemistry and photosynthetic activity in a hot spring microbial mat. Appl. Environ. Microbiol. 48, 270-275.

Sandbeck, K. A., and Ward, D. M. (1981). Fate of immediate methane precursors in low-sulfate, hot-spring algal-bacterial mats. Appl. Environ. Microbiol. $41,775-782$.

Steunou, A.-S., Bhaya, D., Bateson, M. M., Melendrez, M. C., Ward, D. M., Brecht, E., et al. (2006). In situ analysis of nitrogen fixation and metabolic switching in unicellular thermophilic cyanobacteria inhabiting hot spring microbial mats. Proc. Natl. Acad. Sci. U.S.A. 103, 2398-2403. doi: 10.1073/pnas.05075 13103

Steunou, A.-S., Jensen, S. I., Brecht, E., Becraft, E. D., Bateson, M. M., Kilian, O., et al. (2008). Regulation of nif gene expression and the energetics of $\mathrm{N}_{2}$ fixation over the diel cycle in a hot spring microbial mat. ISME J. 2, 364-378. doi: 10.1038/ismej.2007.117
Tank, M., and Bryant, D. A. (2015). Nutrient requirements and growth physiology of the photoheterotrophic Acidobacterium, Chloracidobacterium thermophilum. Front. Microbiol. 6:226. doi: 10.3389/fmicb.2015.00226

Taverner, T., Karpievitch, Y. V., Polpitiya, A. D., Brown, J. N., Dabney, A. R., Anderson, G. A., et al. (2012). DanteR: an extensible R-based tool for quantitative analysis of -omics data. Bioinformatics 28, 2404-2406. doi: 10.1093/bioinformatics/bts 449

Van Der Meer, M. T., Schouten, S., Damste, J. S., and Ward, D. M. (2007). Impact of carbon metabolism on ${ }^{13} \mathrm{C}$ signatures of cyanobacteria and green nonsulfur-like bacteria inhabiting a microbial mat from an alkaline siliceous hot spring in Yellowstone National Park (USA). Environ. Microbiol. 9, 482-491. doi: 10.1111/j.1462-2920.2006.01165.x

Van Der Meer, M. T. J., Klatt, C. G., Wood, J., Bryant, D. A., Bateson, M. M., Lammerts, L., et al. (2010). Cultivation and genomic, nutritional, and lipid biomarker characterization of Roseiflexus strains closely related to predominant in situ populations inhabiting Yellowstone hot spring microbial mats. J. Bacteriol. 192, 3033-3042. doi: 10.1128/JB.01610-09

Ward, D. M. (1978). Thermophilic methanogenesis in a hot-spring algalbacterial mat (71 to 30 degrees C). Appl. Environ. Microbiol. 35, 1019-1026.

Ward, D. M., Bateson, M. M., Ferris, M. J., Kühl, M., Wieland, A., Koeppel, A., et al. (2006). Cyanobacterial ecotypes in the microbial mat community of Mushroom Spring (Yellowstone National Park, Wyoming) as specieslike units linking microbial community composition, structure and function. Philos. Trans. R. Soc. Lond. B Biol. Sci. 361, 1997-2008. doi: 10.1098/rstb. 2006.1919

Ward, D. M., Castenholz, R. W., and Miller, S. R. (2012). "Cyanobacteria in Geothermal Habitats," in Ecology of Cyanobacteria II, ed B. A. Whitton (Rotterdam: Springer), 39-63. doi: 10.1007/978-94-0073855-3_3

Ward, D., Tayne, T., Anderson, K., and Bateson, M. (1987). “Community Structure and Interactions Among Community Members in Hot Spring Cyanobacterial Mats," in Symposia of the Society for General Microbiology (Cambridge).

Xie, G., Zhang, S., Zheng, X., and Jia, W. (2013). Metabolomics approaches for characterizing metabolic interactions between host and its commensal microbes. Electrophoresis 34, 2787-2798. doi: 10.1002/elps. 201300017

Zeng, Y. B., Ward, D. M., Brassell, S. C., and Eglinton, G. (1992). Biogeochemistry of hot-spring environments. 3. Apolar and polar lipids in the biologically-active layers of a cyanobacterial mat. Chem. Geol. 95, 347-360. doi: 10.1016/00092541(92)90021-V

Conflict of Interest Statement: The Guest Associate Editor, William P. Inskeep, declares that although he has promoted collaboration in this research topic, he is not directly involved with the research reported in this paper, and has no relationship with the independent reviewers who provided comments to the manuscript. $\mathrm{He}$ confirms that the review process was handled objectively and that no conflict of interest exists. The authors declare that the research was conducted in the absence of any commercial or financial relationships that could be construed as a potential conflict of interest.

Copyright (c) 2015 Kim, Nowack, Olsen, Becraft, Wood, Thiel, Klapper, Kühl, Fredrickson, Bryant, Ward and Metz. This is an open-access article distributed under the terms of the Creative Commons Attribution License (CC BY). The use, distribution or reproduction in other forums is permitted, provided the original author(s) or licensor are credited and that the original publication in this journal is cited, in accordance with accepted academic practice. No use, distribution or reproduction is permitted which does not comply with these terms. 